\title{
TRAFICANDO CON HOMBRES: LA ANTROPOLOGÍA DE LA MASCULINIDAD
}

\author{
Matthew C. Gutmann \\ Brown University - Estados Unidos
}

Resumen: La antropología siempre ha tenido que ver con hombres hablando con hombres sobre hombres, no obstante es bastante reciente el que dentro de la disciplina unos pocos hayan realmente examinado a los hombres como hombres. Este articulo explora el cómo entienden, utilizan y discuten los antropólogos la categoría de masculinidad mediante la revisión de análisis recientes sobre los hombres como sujetos que tienen género a la vez que lo otorgan. Se comienza con las descripciones de cuatro formas distintas de definición y tratamiento de la masculinidad en la antropología, y se presta atención especial a las relaciones de diferencia, desigualdad, y mujeres con el estudio antropológico de las masculinidades, incluida la curiosa omisión de la teoría feminista por patie de numerosos antropólogos estudiosos de lo varonil. Los temas específicos que se discuten abarcan las diversas economías culturales de la masculinidad, la noción de regiones culturales en relación a las imágenes de hombría, amistad masculina, machismo, corporalidad masculina, violencia, poder, y fisuras sexuales.

Palabras clave: cuerpo, machismo, masculinidad, relaciones de género.

Resumo: A antropologia sempre foi uma questão de homens falando com homens sobre homens. Apenas recentemente, alguns poucos antropólogos começaram a estudar homens enquanto homens. Este artigo considera como estes antropólogos entendem, usam e discutem a categoria de masculinidade em análises recentes. Iniciamos com a descrição de quatro maneiras distintas de definir e tratar a masculinidade, chamando atenção inclusive para a omissão curiosa da teoria feminista por parte de muitos pesquisadores. Prosseguimos com a reflexão sobre as diversas economias culturais da masculinidade, a noção de regiões culturais em relação às imagens de bravura, amizade masculina, machismo, corporalidade masculina, violência, poder, e fissuras sexuais.

Palavras-chave: corpo, machismo, masculinidade, relações de gênero. 


\section{Introducción: cuestiones conceptuales}

La antropología desde siempre se ha ocupado de hombres hablándole a hombres sobre hombres. Sin embargo hasta hace poco tiempo, fueron contados aquellos quienes dentro de la disciplina del "estudio del hombre" realmente examinaron a los hombres como hombres. Aunque durante las dos últimas décadas el estudio de género conforma el cuerpo teórico y empírico nuevo más importante dentro de la antropología en su conjunto, los estudios de género aún son equiparados con los estudios de las mujeres.

Los nuevos análisis sobre los hombres como sujetos con género y que otorgan género constituyen actualmente la antropología de la masculinidad. Existen al menos cuatro formas distintas mediante las cuales los antropólogos definen y usan el concepto de masculinidad y las nociones relativas a la identidad masculina, la hombría, la virilidad y los roles masculinos. La mayoría de los antropólogos que trabaja el tema utiliza más de uno de estos conceptos, lo cual permite señalar la fluidez de los conceptos y la lamentable falta de rigor teórico en el abordaje del tema.

El primer concepto de masculinidad sostiene que ésta es, por definición, cualquier cosa que los hombres piensen y hagan. El segundo afirma que la masculinidad es todo lo que los hombres piensen y hagan para ser hombres. El tercero plantea que algunos hombres, inherentemente o por adscripción, son considerados "más hombres" que otros hombres. La última forma de abordar la masculinidad subraya la importancia central y general de las relaciones masculino-femenino, de tal manera que la masculinidad es cualquier cosa que no sean las mujeres.

Hasta la fecha, en la literatura antropológica sobre la masculinidad se ha hecho mucho énfasis en cómo los hombres en contextos culturales diferentes desempeñan su propia hombría y la de otros. Herzfeld (1985, p. 16, 47) señaló la importancia que para los hombres de una aldea en Creta revestía el distinguir entre "ser un buen hombre” y "ser bueno como hombre”, por que aquí lo que cuenta es la "excelencia en el desempeño" de la hombría, más que el simple hecho de haber nacido varón.

En su estudio etnográfico sobre una "subcultura masculina" entre los Sambia de Nueva Guinea, Herdt (1994, p. 1) se propone presentar “cómo los hombres se perciben a sí mismos como personas masculinas, sus tradiciones rituales, sus mujeres, y el cosmos...”. La forma de comprender la masculinidad 
Sambia, según Herdt, es por consiguiente prestar mucha atención al lenguaje masculino, vale decir, a lo que estos hombres dicen sobre sí mismos como hombres. Además, al explorar las iniciaciones masculinas entre los Sambia, Herdt (1994, p. 322) enfatiza lo que denomina "una masculinidad fálica, tan intensa" que de lo que se trata no es de que los varones se esfuerzan por alcanzar la masculinidad por oposición a la feminidad, sino de lograr una clase específica de masculinidad, la cual por su naturaleza misma, es solamente accesible para los hombres. (Ver también la premisa de Gregor (1985) referida a que para los Mehinaku del Brasil, al igual que para otros grupos en otras partes, "la identidad masculina tiene una fundamentación anatómica"). No obstante, Herdt (1994, p. 17) sostiene que si bien no es el "dogma público" de los hombres, para los Sambia "la masculinidad misma emerge de la feminidad".

En el primer gran estudio antropológico sobre la masculinidad, Brandes (1991) describió cómo las identidades masculinas se desarrollan relacionadas con las mujeres. En su examen del folklore y los hombres en la Andalucía rural, Brandes sostuvo que aún si las mujeres no están físicamente presentes con los hombres mientras estos trabajan o beben, y si no son reflejadas en los pensamientos concientes de los hombres, la "presencia” de las mujeres es un factor significativo en la comprensión subjetiva de los hombres de lo que para ellos significa ser hombres. En la discusión acerca de las identidades de género en sectores de clase obrera de Ciudad de México, Gutmann (1998) planteó que la mayoría de los hombres durante la mayor parte de sus vidas perciben sus identidades masculinas a partir de las comparaciones que hacen con las identidades femeninas.

La atención prestada en la antropología a los hombres-como-hombres (Godelier, 1986; Ortner; Whitehead, 1981) ha sido insuficiente, y buena parte de lo que los antropólogos han escrito sobre la masculinidad debe inferirse de la investigación realizada sobre las mujeres y por extrapolación de estudios sobre otros temas.

Además de marcos de referencia conceptuales diferentes, existen dos enfoques temáticos distintos en el estudio antropológico de la masculinidad. Algunos estudios se ocupan primordialmente de hechos relacionados exclusivamente con hombres tales como la iniciación masculina y el sexo entre hombres, las organizaciones exclusivamente masculinas como los cultos de hombres, y lugares exclusivos para hombres, tales como casas y bares para varones. Otros estudios incluyen descripciones y análisis de las mujeres como 
parte integral del estudio más amplio de lo varonil y la masculinidad. Como ejemplo del primer caso se puede citar la muy leída encuesta de Gilmore (1990). Este estudio, de orientación funcionalista, insiste en el carácter omnipresente, aunque no necesariamente universal, del imaginario masculino en el mundo, y en un arquetipo y "estructura profunda” de masculinidad subyacentes transcultural y transhistóricamente. El otro enfoque ha sido el de documentar la naturaleza ambigua y fluida de la masculinidad dentro de contextos espaciales y temporales específicos, lo cual ha suministrado evidencia implícita para el argumento de Yanagisako y Collier (1987) según el cual no existe un "punto de vista masculino" único.

Luego de seguirle la pista a ciertos antecedentes históricos para el estudio contemporáneo de la masculinidad, la revisión se ocupa de temas más amplios que los antropólogos han relacionado recientemente con los hombres y la virilidad, tales como el carácter nacional; las divisiones del trabajo; los lazos familiares, de parentesco y de amistad; el cuerpo; y las luchas por el poder. Debido a la ausencia de un esfuerzo teórico sistemático sobre la masculinidad, la mayoría de los estudios antropológicos referidos a los hombres-como-hombres, se centran solamente en uno o dos de estos temas, creando categorías y definiciones múltiples y contradictorias sobre los hombres.

\section{El varón histórico en la antropología}

“El muchacho Arapesh cultiva a su esposa”, escribió Mead (1982). De igual forma, históricamente, los antropólogos han cultivado a sus hombres nativos: las pretensiones de los etnógrafos de haber descubierto una masculinidad exótica (u omnipresente) en los rincones más lejanos del planeta siempre se han fundamentado en las contribuciones centrales de los propios antropólogos a la creación de categorías de masculinidad y sus opuestos en diversos medios culturales. Desde el interés de Malinoswki (1929) en los impulsos sexuales (tanto de los nativos como de los antropólogos), la autoridad masculina (y cómo puede encontrarse en hombres fuera del padre), y el complejo de Edipo, hasta Evans-Pritchard (1974) -para quien, como lo afirma Ardener (1989), las mujeres y el ganado eran importantes y omnipresentes, e igualmente mudos- los antropólogos han desempeñado un papel no del todo insignificante en el desarrollo y popularización de definiciones y diferenciaciones 
"nativas" sobre la masculinidad, la feminidad y la homosexualidad, entre otras. Retrospectivamente, es bastante difícil aclarar hasta dónde los puntos de vista expresados han representado los de hombres, mujeres, o antropólogos -o una combinación de todos ellos.

Cuando la antropología como disciplina apenas estaba tomando forma, los círculos intelectuales en Europa y Estados Unidos estaban experimentando lo que Mosse (1996, p. 78) denomina los retos de fin de siglo a la masculinidad y a los hombres modernos como la categoría "no marcada": los hombres "no varoniles" y las mujeres "no femeninas" se están haciendo cada vez más visibles. Estos retos y el movimiento a favor de los derechos de las mujeres han puesto en peligro aquella división de género clave para la construcción de la masculinidad moderna. Con todo este cuestionamiento sexual, de nuevo el llamado de las sirenas de los mares del Sur resultó ser demasiado para los sugestionables europeos. Si para algunos antropólogos, por ejemplo, los hombres de Tahiti parecían ser más libres para expresar su sexualidad masculina, esto se atribuyó en gran medida a una cierta cualidad infantil de los hombres en estos contextos "primitivos".

El trabajo de Margaret Mead en el Pacífico ofreció una información sorprendente y contraria a las nociones populares existentes en Occidente sobre la adolescencia y la sexualidad; así mismo desestabilizó muchos supuestos acerca de la masculinidad y la femineidad como cualidades inherentes. Cuando escribió sobre el carácter ambiguo y contradictorio del género, Mead (1982) planteó: "Encontramos que los Arapesh -tanto hombres como mujeres- hacen gala de una personalidad que, al ser externa a nuestras nociones históricamente limitadas, podríamos denominar como maternal en sus aspectos relativos al parentesco, y femenina en sus aspectos sexuales”. En su elaboración acerca del "dilema del individuo cuyos impulsos análogos no son considerados en las instituciones de su cultura”, Ruth Benedict (1934, p. 262), también optó por resaltar la diversidad de las masculinidades y demostró que la homosexualidad ha sido históricamente considerada anormal solamente en algunas sociedades.

Antropólogos posteriores, incluidos aquellos asociados de alguna manera con la escuela de la cultura y la personalidad durante la Segunda Guerra Mundial y la década de 1950, continuaron probando similitudes y diferencias comparativas relacionadas con la participación de los hombres en la crianza de los hijos, las estructuras de personalidad masculinas, la orientación masculina hacia la guerra, los ritos masculinos de iniciación y socialización, el 
simbolismo del pene, entre otros. En forma creciente, se relacionaron modelos bifurcados de dualismos hombre-mujer con rasgos del carácter nacional más “femeninos” y más “masculinos” (ver Herman, 1995). Respecto a las premisas no examinadas sobre la dominación masculina universal y las diferencias universales de los roles-sexos, ninguna teoría tuvo tanta influencia en las ciencias sociales durante la época de la postguerra como la de Parsons y Bales (1955), quienes presentaron a las mujeres como expresivas (emocionales) y a los hombres como instrumentales (pragmáticos, racionales, y cognitivos). La biología en última instancia, determinaba lo que hombres y mujeres hacían diferencialmente en la familia. Por lo general, la "naturaleza humana" ha sido un código referido a la importancia fundamental atribuida a determinadas capacidades musculares y reproductivas, las cuales a su vez según algunos, tienen como resultado inevitable patrones socioculturales relacionados con la caza y lo doméstico (ver también Friedl, 1984).

Lévi-Strauss trató de aclarar ciertas cuestiones centrales, sin embargo debe resaltarse que en Las estructuras elementales del parentesco (LéviStrauss, 1991a) -un clásico muy influyente en la primera generación de antropólogas feministas responsables de iniciar los estudios de género en forma profunda- escasamente menciona categorías tales como hombres, masculinidad, mujeres y femineidad. Lo que aparece con bastante frecuencia es la referencia a los hombres a través del eufemismo: como ejemplo, los hombres son llamados "los dadores de esposas". Al igual que sucedió con los primeros estudios antropológicos feministas en la década de 1970, los primeros enfoques empleados para estudiar la masculinidad tendían a mostrar un mundo demasiado dicotomizado en el cual los hombres eran hombres y las mujeres eran mujeres, y donde las mujeres contribuían tan poco a la "construcción” de los hombres como éstos a la "construcción" de las mujeres. A diferencia de estos primeros estudios antropológicos feministas sobre las mujeres, los cuales trataban de resaltar la "invisibilidad" anterior de las mujeres en el canon, los hombres nunca han sido invisibles en la etnografía o en las teorías sobre el "género humano".

\section{Las economías culturales de la masculinidad}

En los últimos quince años, han aparecido en inglés y otros idiomas, varias etnografías y volúmenes editados sobre la masculinidad (ver 
Castelain-Meunier, 1988; Leal, 1992; Welzer-Lang; Pichevin, 1992). Algunos de estos estudios han sido realizados por antropólogos prominentes. Los enfoques y conclusiones teóricas de estos estudios difieren considerablemente, no obstante, los mejores han acertado al plantear interrogantes específicos sobre lugares y situaciones históricas determinados, a la vez que la mayoría ha evitado caer en una desafortunada reacción de "yo también” frente a la antropología feminista. Aquellos que han intentado hacer generalizaciones referidas a "culturas" enteras de poblaciones supuestamente homogéneas han tendido a reinventarse muchos de los mismos calificativos desgastados con los cuales los "hombres" (e.g. los hombres de la América Latina urbana, del sur de España o de las tierras altas de Nueva Guinea) han sido calificados como representativos de uno u otro paradigma de las ciencias sociales.

\section{Regiones culturales y cuestiones de fronteras}

Las cuestiones sobre la virilidad y las definiciones de la masculinidad han sido frecuentemente puestas sobre el tapete en las confrontaciones entre el colonizador y los colonizados. Tal como concluyó Stoler (1991, p. 56), "La desmasculinización de los hombres colonizados y la hipermasculinidad de los varones europeos representan afirmaciones fundamentales de la supremacía blanca” (ver también Fanon, 1967). Debido en parte a la dinámica interna de la antropología y en parte a las exigencias planteadas por el reordenamiento imperial de la segunda posguerra, el estudio de la masculinidad en la antropología ha estado ligado con frecuencia a los estudios de áreas culturales. En relación a “los ideales de virilidad” en el Mediterráneo, Gilmore (1990, p. 48) por ejemplo planteó "tres imperativos morales: primero, embarazar a la esposa; segundo, proveer a los dependientes; tercero, proteger la familia”. El argumento es que estos propósitos y cualidades específicas son, en forma significativa, más marcados en esta área cultural que en cualquier otro lugar del mundo. Los antropólogos que se inclinan a equiparar a "la nación” exclusivamente con los hombres en estas sociedades han, de forma poco sorprendente, tendido también a minimizar las contribuciones de las mujeres a la masculinidad y a los rasgos nacionales. (Ver también Mernissi, 1987 y Knauss, 1987 sobre los ideales con contenido de género asociados con el Islam en el Medio Oriente).

Por otro lado, estudiosos como Strathern consideran que al examinar las relaciones masculino-femenino, algunos argumentos acerca de las 
particularidades propias de un área han sido exageradas. Strathern (1988, p. 64) afirmó, “ Creo que en forma demasiado axiomática el modelo rol-sexo ha tenido peso en los análisis antropológicos de la iniciación en las tierras altas (de Nueva Guinea) y del antagonismo masculino-femenino" (ver también Bowden, 1984). Herdt y Stoller (1990, p. 352-353) concluyen que "para el estudio de lo erótico y de la identidad de género, los datos transculturales son aún demasiado pobres y descontextualizados para poder realmente comparar la masculinidad y la feminidad, la excitación sexual y las fantasías de personas de diferentes culturas”. [Sobre esfuerzos recientes en esta dirección, ver Parker et al. (1992) y Parker y Gagnon (1995)]. En su crítica de la "cultura mediterránea”, Herzfeld (1987, p. 76) sostiene que "Los etnógrafos pueden haber contribuido involuntariamente a la creación de un estereotipo" y han creado una profecía que se cumple a sí misma, un argumento que puede extenderse para criticar el regionalismo cultural de la masculinidad.

Lo masculino y lo femenino varían culturalmente, y las prácticas y creencias sexuales son contextuales, no obstante el contexto cultural no necesariamente es equivalente a los rasgos de la cultura nacional. Adicionalmente, la mayoría de los antropólogos que han escrito acerca de la masculinidad en las últimas dos décadas han considerado que se justifica discutir las transformaciones en curso en coyunturas culturales diferentes: Herdt (1993, p. xxxii) señaló "la forma igualitaria (que) parecería ser una importación cultural de la modernización” en Nueva Guinea, en tanto que Keesing (1982), p. 16) reconoció potenciales reacciones "regionales" a la occidentalización como una posible “perpetuación o renacimiento del culto a lo masculino”. Brandes (1991) anotó que en Andalucía "las normas sociales existentes entre las personas menores de veinticinco o veinte años parecen distanciarse bruscamente de las compartidas por sus padres”, y Herzfeld (1985) describió “transformaciones" modernas en Creta. En su conjunto, el énfasis puesto por Gayle Rubin (1986) sobre los cambios y transiciones trascendentales operadas en las relaciones de género y de sexo es correcto, como también lo es su suspensión temporal del dictamen de la exterminación prematura para "el sexo ofensor”.

En estos estudios etnográficos sobre los hombres, la influencia a veces indirecta, de ciertas corrientes teóricas claves es evidente, empezando por las obras de Marx y Freud (ver Laqueur, 1994) y más recientemente por las referencias a Foucault (1977, 1980), Merleau-Ponty (1962), y Bourdieu (1980, 1995, 1997). 


\section{Divisiones del trabajo por género}

Otro elemento de la economía cultural de la masculinidad que merece atención tiene que ver con las marcadas diferencias existentes entre lo que hombres y mujeres hacen en sus actividades y labores diarias. La mayoría de los etnógrafos, siguiendo el ejemplo de Durkheim (1984), han tratado de documentar estas divisiones del trabajo y sobre esa base hacer generalizaciones más amplias respecto a las desigualdades culturales. Delaney (1991, p. 251) por ejemplo, anotó la separación física por razones de género en una aldea de Turquía: "Fuera de la actividad sexual y de la alimentación, la única otra actividad en la cual hombres y mujeres pasan períodos extendidos de tiempo juntos es trabajando en el bahce (jardín)”, indicación de las desigualdades de poder entre hombres y mujeres, emanadas de fundamentos teológicos en esta área. Godelier (1986) concluyó que entre los Baruya de Nueva Guinea, las divisiones del trabajo según género presuponen, más que originan, la dominación masculina, en la medida en que las mujeres son excluidas de la propiedad de la tierra, de las herramientas importantes, y de los objetos sagrados, entre otras cosas. Un artículo de Richard Lee (1968) demostró que durante los años cincuenta por lo menos, el trabajo de las mujeres recolectando nueces y granos aportaba una mayor cantidad de calorías a la dieta de los !Kung San en el sur de África que las actividades de caza de los hombres, ofreciendo así evidencia de que las contribuciones de las mujeres dentro de esta sociedad de recolectores eran mayores no solamente en relación a la crianza de los hijos sino en términos del mantenimiento de los adultos. Debe señalarse como saludable el desarrollo encontrado en recientes estudios de género relacionado con el intento de describir y analizar las divisiones del trabajo no como tipos ideales estáticos y formales, sino tal como se presentan en sus manifestaciones culturales e históricas actuales y contradictorias.

\section{La familia}

\section{Parentesco y matrimonio}

Weeks (1985, p. 159) advirtió que "La narración de Lévi-Strauss sobre el significado fundante del intercambio de mujeres”, "presupone de entrada 
que son los hombres quienes, por ser naturalmente promiscuos, los que están en condiciones de intercambiar sus mujeres”. Aunque ciertos antropólogos han presentado evidencia que no contradice o atenúa y que apoya la teoría fundacional de Lévi-Strauss sobre el intercambio masculino de mujeres, otros han encontrado motivos para cuestionar una descripción tan uniforme del matrimonio. Al explorar las relaciones de género en la sociedad malaya del siglo diecinueve, Peletz (1996, p. 88) mostró que “en la práctica, aunque no necesariamente en la ideología local (oficial), los hombres eran intercambiados por las mujeres y no por otros hombres”. Peletz (1996, p. 97) llama la atención sobre un problema conceptual, específicamente respecto a la "preocupación sobre las formas de intercambio y el descuido relativo de los contenidos y estrategias de intercambio" presentes en Lévi-Strauss.

En su trabajo sobre la matrifocalidad en Guayana, Raymond Smith (1956) reconceptualizó las dinámicas de poder al interior de los hogares, de la herencia, y sencillamente del "lugar de los hombres" en las vidas de muchas familias. [Para un tratamiento reciente de estos temas, ver Brana-Schute (1979)]. Lomnitz y Pérez-Lizaur (1993) encontraron que en las élites de ciudad de México, la "centralización de las mujeres” y la preeminencia de la "gran familia” revelan mucho sobre los límites del poder masculino, no solamente en las familias sino también en las compañías que estas familias manejan y de las cuales son propietarias. Respecto a los términos para referirse al parentesco, el estudio de Carol Stack (1974) sobre mujeres afro-americanas en el sur de Illinois fué el primero en poner en duda la comprensión fácil de los identificadores “madre” y “padre”. Stack encontró que los roles de los hombres como padres dependían primordialmente no de sus relaciones con los hijos sino de las relaciones de los hombres con las madres de los hijos.

\section{El ejercicio de la paternidad - ser padre}

A partir de los estudios de John y Beatrice Whiting sobre la crianza de los hijos en los años de 1950, los significados de la paternidad y las prácticas de los padres han sido examinadas transculturalmente en forma detallada. Al documentar la ausencia del padre, los ritos de la circuncisión, los ritos de iniciación masculinos, cómo duermen los niños, la envidia por la posición, y lo que se ha denominado laxamente como hipermasculinidad y supermasculinidad, los Whiting y sus estudiantes, colegas y críticos han escrito sobre los parámetros 
biológicos dentro de los cuales puede florecer la diversidad cultural en las sociedades humanas (ver, por ejemplo, Broude, 1990; Cath; Gurwitt; Gunsberg, 1989; Hollos; Leis, 1989; Parker; Parker, 1992; West; Konner, 1976; Whiting, 1963; Whiting; Whiting, 1975; Whiting; Kluckhohn; Anthony, 1958).

La evidencia respecto a las experiencias de ser padre es bastante abundante en la antropología. Al escribir sobre la Irlanda rural en los años setenta, Scheper-Hughes (1979, p. 148) explicaba que lejos de ser ineptos por naturaleza para desempeñar el papel de padres, "los hombres son socializados para que se sientan inadecuados y torpes en extremo con los bebés”. En su trabajo posterior en un tugurio en el nordeste del Brasil, Scheper-Hughes (1992, p. 323-325) señalaba que los "padres" son los hombres que proveen leche en polvo a los bebés, llamada popularmente "leche del padre”, y que a través de este regalo se establece la legitimidad simbólica del hijo. El trabajo de Taggart (1992) en la región de la Sierra Nahua de México muestra que, hasta hace poco, la mayoría de los niños dormían con su padre y no con su madre desde el destete hasta la pubertad. En su encuesta cuantitativa acerca del cuidado de los hijos por parte del padre entre los pigmeos Aka, Hewlett (1991, p. 168) informó que "los padres Aka gastan el 47 por ciento de su día alzando o encontrándose a un brazo de distancia de sus niños pequeños, y mientras los alzan, es más probable que sean los padres y no las madres quienes los abracen y los besen”. [Ver también Read (1952) para un primer documento sobre los asuntos de los hombres Gahuku-Gama, y Battaglia (1985) sobre la crianza paterna de los Sabarl en Nueva Guinea.]

Gutmann (1998) se apoya en Lewis (1968) y otros para examinar el patrón histórico en el México rural por medio del cual los hombres desempeñan un papel más significativo en la crianza de los hijos varones de lo que pueda ser el caso entre los proletarios urbanos (ver también Fuller, 1998). No obstante, concluye que para muchos hombres y mujeres de las comunidades de invasión en México, el ser un padre activo, consistente y a largo plazo, es un elemento crucial en lo que significa ser un hombre y en lo que hacen los hombres.

Para resaltar las cuestiones de clase e historia, y las contradicciones de ser padre en la ciudad de Nueva York, Bourgois (1995, p. 316) cita a un joven puertorriqueño:

Estuve saliendo con esta señora de la calle 104 durante tres años; ella tiene cinco hijos; ninguno de ellos es mío; y yo los cuidaba, mano. En los días de escuela, 
yo les compraba la ropa para el primer día de clases, y toda esa mierda. Usted debía haberme visto, cómo robaba radios de los carros, como un loco. Forzar los carros- conseguir tres, cuatro, cinco radios en una noche solamente para comprarles zapatos nuevos.

\section{La amistad masculina}

El tema de los espacios masculinos, la segregación de los hombres y lo que Sedgwick (1985) denomina homosociabilidad, ha recibido reconocimiento etnográfico pero poco análisis sistemático. En las casas secretas de los hombres en varias sociedades (Poole, 1982; Tuzin, 1982, 1997), en los enclaves exclusivamente masculinos tales como cafés o lugares para consumir alcohol con otros (Brandes, 1987; Cowan, 1990; Duneier, 1992; Herzfeld, 1985; Jardim, 1992; Lewgoy, 1992; Limón, 1994; Marshall, 1979), en las relaciones de dependencia del cuatismo y en la "solidaridad de comensales" (ver Lomnitz, 1975 y Papataxiarchis, 1991, respectivamente) y en el desempleo entre los jóvenes de clase obrera (ver Willis, 1979), y en los deportes para hombres (ver Alter, 1992; Wacquant, 1995a, 1995b), la exclusividad de los hombres ha sido mejor documentada que entendida. Al emplear el trabajo de Bourdieu sobre el cuerpo (e.g. Bourdieu, 1980), los estudios de Wacquant (1997) del "libido sexualis (heterosexual)" y del "libido pugilistica (homoerótico)” entre los boxeadores africano-americanos en Chicago, son notables por la construcción teórica que hace sobre la masculinidad (y lo que determina que algunos hombres sean más “varoniles”) y los cuerpos masculinos así como por el detalle etnográfico.

Un tema central en la discusión de la amistad masculina es la "creación de vínculos masculinos” (male bonding), término inventado por el antropólogo Lionel Tiger (1984, p. 208) con la explicación de que los "hombres 'necesitan' algunos lugares y/o ocasiones donde se excluyan a las mujeres”. A pesar de que la frase "creación de vínculos masculinos” ya forma parte del lenguaje común en los Estados Unidos como descripción abreviada de camaradería masculina (y frecuentemente usada en forma despectiva), Tiger acuñó el término tratando de ligar supuestos impulsos inherentes en los hombres (a diferencia de las mujeres) con los cuales los hombres demuestran solidaridad entre sí. La “creación de vínculos masculinos” señaló Tiger (1984, p. 135), es un rasgo desarrollado a lo largo de miles de años, "un proceso con raíces 
biológicas conectado...con el establecimiento de alianzas necesarias para la defensa del grupo y de la cacería”.

Connell (1995, p. 46) contextualiza históricamente la teoría sobre la “creación de vínculos masculinos” de Tiger: "Desde que se derrumbó la capacidad que tenía la religión de justificar la ideología de género, la biología ha sido llamada a llenar el vacío”. Así, que con sus genes masculinos, se dice que los hombres heredan tendencias a la agresión, la vida familiar, la competitividad, el poder político, la jerarquía, la promiscuidad y demás. La influencia de un análisis tan "naturalizado" se extiende más allá de los confines de la antropología y de la academia para justificar la exclusión de las mujeres de los dominios masculinos claves. En el Movimiento de los Hombres Nuevos de los Estados Unidos (para una etnografía de este movimiento, ver Schwalbe, 1996; para su filosofía, ver Bly, 1992), la masculinidad como hecho biológico, autenticada por medio de la genitalidad y la antropología "pop”, ha sido elevada al nivel de los vínculos místicos.

\section{El cuerpo}

\section{Fisuras somáticas}

El componente erótico en la creación de vínculos masculinos y la rivalidad masculina está claramente demostrado en muchos estudios recientes sobre sexo con el mismo sexo. El artículo de Weston (1993) acerca de los estudios de lesbianismo y homosexualidad en la antropología constituye la mejor revisión a la fecha de la manera como la disciplina ha abordado este tema; acá resalto sólo unos puntos adicionales. Muchos estudios en la antropología de la masculinidad tienen como componente central el informar y analizar algún tipo de relaciones, atracciones y fantasías sexuales entre varones (Almaguer, 1991; Carrier, 1995; Cohen, 1995a, 1995b; Herdt, 1982, 1987, 1994; Lancaster, 1992, 1997a, 1997b, 1998; Parker, 1994; Roscoe, 1991; Wilson, 1995). Es de gran importancia teórica el que el término "homosexualidad” está encontrando cada vez más rechazo, al considerárselo demasiado limitado en lo que se refiere a su significación e implicaciones (ver Elliston, 1995). Tal como lo planteó Herdt (1994, p. xiii-xiv), "Ya no es útil considerar que los Sambia practican la 'homosexualidad' por los significados confusos que tiene este concepto y por sus sesgos intelectuales en la historia occidental de la sexualidad”. 
Los grandes estudios antropológicos sobre los hombres que sostienen relaciones sexuales con otros hombres se iniciaron con el estudio que Esther Newton (1972) hizo de las reinas "drag” ( de Joseph Carrier de 1972 acerca de "los encuentros homosexuales de los varones mexicanos urbanos" (ver Carrier, 1995), aunque otros trabajos sobre el sexo con el mismo sexo sólo hicieron su aparición en forma regular dentro de la disciplina una década después. Sigue vigente la importancia del planteamiento de Chodorow (1994) según cual la heterosexualidad al igual que la homosexualidad es un fenómeno problemático e insuficientemente estudiado, especialmente si se considera a la sexualidad como algo más que el contacto corporal genital y reproductivo. (Ver también Greenberg, D., 1988; Katz, 1990; Rubin, 1993).

Anteriores estudios antropológicos se ocuparon de la sexualidad y de los cuerpos masculinos (e.g. Malinowski, 1973, 1983) y trabajos más recientes trataron el tema pero no la nomenclatura de la masculinidad (e.g. Spiro, 1982), fué sólo a principios de la década de 1970, debido a la influencia política del feminismo, de los estudios sobre la homosexualidad y el lesbianismo, y el desafío teórico de Foucault y otros como Jeffrey Weeks, que los antropólogos comenzaron a explorar en forma sistemática la relación entre los cuerpos materiales y las relaciones culturales.

Al escribir sobre la cultura sexual en el Brasil, Parker (1994) anotó: “Está claro que en la época moderna, la sexualidad centrada en la reproducción, se ha convertido en algo que debe ser manejado no solamente por la Iglesia Católica o por el estado, sino por los individuos mismos”. Asi mismo, al reflexionar sobre la tensión entre cuerpos y tecnologías sociales, Cohen (1995b) orienta la discusión antropológica del deseo sexual y los cuerpos en otra dirección al analizar la pornografía política de la ciudad de Banaras en el norte de la India. Cuando escribe sobre el sufrimiento social diferencial entre hombres y mujeres víctimas del polio en la China, Kohrman (1997) señala que "para los hombres, los aspectos más difíciles tienen que ver con la inmovilidad”, en tanto que para las mujeres, "su dolor parece centrarse en la imperfección corporal”. Un área de la indagación antropológica relacionada con los hombres que parece bastante precaria tiene que ver con la prostitución; a pesar de que existen algunos materiales etnográficos sobre varones prostitutos, se necesita mejor documentación sobre las relaciones de los hombres con las mujeres prostitutas. 
Las fisuras somáticas se cruzan en muchos casos, como en la insinuación ritual que los hombres hacen de si mismos en las labores físicas de la reproducción mediante la covada, la cual se analiza generalmente corno una afirmación de la paternidad social, un reconocimiento del papel del marido en el parto, una revelación de las cualidades femeninas de los hombres, y como un reflejo del deseo de los hombres de imitar las habilidades reproductivas de las mujeres, vale decir, “envidia de la matriz” (ver Moore, 1991; ver también Paige; Paige, 1981). Es interesante comparar la covada con las observaciones de Ginsburg (1990, p. 64) sobre el movimiento pro-vida de Dakota del Norte en Estados Unidos, donde el "aborto se fusiona con el imaginario de una sexualidad destructiva, decadente y por lo general masculina”. Tal comprensión a su vez está vinculada con la relación entre sexualidad y dominación masculina: Según Godelier (1986) la sexualidad masculina entre los Baruya se usa para mantener los mecanismos de la dominación masculina, la producción de "grandes hombres" y la ideología que justifica el orden social en su conjunto (ver también Godelier; Strathern, 1991).

\section{Fisuras sexuales: "tercer género", personas con dos espíritus, e hijras}

Los orígenes de la expresión “tercer género”, muy popularizada en los estudios culturales, lésbicos y homosexuales, pueden ser parcialmente rastreados en las investigaciones sobre género y prácticas sexuales que no pueden ser fácilmente categorizadas como heterosexuales u homosexuales. Pero no toda tercería es semejante, y esta formulación puede reificarse como un dogma esencialista. En su narración etnohistórica acerca de un "hombre-mujer" Zuni del siglo diecinueve, Roscoe (1991, p. 2) señaló que We’wha "era un hombre que combinaba el trabajo y los roles sociales de hombres y mujeres, un artista y un sacerdote que se vestía, al menos parcialmente, con ropas de mujer”. Aunque esta forma de vestir (cross-dressing) de nativos norteamericanos -hasta hace poco denominada berdache por los antropólogos-disminuyó como práctica a comienzos del siglo veinte, los hombres de muchas tribus continuaron mostrando una preferencia hacia el trabajo de las mujeres y/o a sentirse atraídos por otros hombres. Con la introducción de un volumen cuya intención era la de reemplazar el término "berdache" por el de "personas con dos espíritus”, Jacobs (Jacobs; Thomas; Lang, 1997) sostuvo que el “[el término ‘berdache’ (sic) tal como lo usan los antropólogos es anacrónico, anticuado 
y no refleja las conversaciones nativas norteamericanas contemporáneas sobre la diversidad de géneros y las sexualidades”. (Para trabajos anteriores sobre berdache ver también Whitehead, 1981 y Williams, 1988).

Al escribir sobre los hijras del norte de la India, los cuales podrían ser sometidos a la castración o a la penectomía o congénitamente "no ser ni hombre ni mujer”, Cohen (1995a) explica por qué el “tercer género” no puede ser una categoría confiable (ver también Nanda, 1990). En igual sentido, Robertson (1992, p. 422) se refiere a la androginia en el teatro japonés, "A pesar del funcionamiento de un principio normalizador, se da el caso que en el Japón.. ni la femineidad ni la masculinidad han sido consideradas como de la incumbencia exclusiva de cuerpos femeninos o masculinos". (Sobre el transvestismo en Samoa, ver Mageo, 1992; sobre el transvestismo en Sardinia, ver Counihan, 1985).

\section{Los objetos del deseo corporal}

Herzfeld (1985, p. 66) anota que según los hombres de la Grecia rural, las mujeres son "pasivas, indecisas e incapaces de controlar su sexualidad o sus temperamentos” (ver también Herzfeld, 1991). Brandes (1991) señala que en Andalucía, de nuevo según los hombres, las mujeres no son consideradas pasivas, sino que son ampliamente conocidas por ser "seductoras, poseídas por apetitos lujuriosos insaciables”. Brandes (1991) también anota que los hombres con frecuencia se sienten amenazados por su atracción hacia las mujeres "la cual se centra principalmente en el trasero femenino", y por transferencia, muchos hombres pueden sentir ansiedad respecto a su propia penetración anal potencial. Dundes (1978) también ofrece un marco de referencia analítico para el análisis de las preocupaciones homoeróticas de los hombres relacionadas con los traseros.

Si en términos generales los etnógrafos han concluido que son pocos los hombres que equiparan su virilidad con sus genitales, son muchos los estudios que indican que son un punto de referencia favorito. Entre los hijras, de acuerdo a Nanda (1990, p. 24), "la castración es la principal fuente del poder ritual”, parecido tal vez a lo que Gayle Rubin (1994, p. 79), en su crítica a la degradación de los enfoques sicoanalíticos, denomina "phallus ex machina". De hecho, es mucha la tinta que se ha gastado en la antropología tratando de examinar comparativamente el papel del semen. Entre los Sambia, Herdt (1994, p. 181) informa que "el temor a que se agote el semen es esencial dentro del 
punto de vista masculino". Como lo anota Herdt (1994, p. 236) en forma por demás conocida, el propósito de las repetidas inseminaciones orales hechas por muchachos mayores a muchachos menores es el de "crear un fondo de virilidad". La experiencia subjetiva violenta y traumática de los cultos masculinos es analizada por Poole (1982) como transformaciones rituales inducidas referidas a la persona, el ser y el cuerpo, practicadas por los Bimin-Kuskusmin de Papua Nueva Guinea. Brandes (1991) señala que en Moteros, España, de la misma manera que se cree que la leche materna existe en cantidad limitada, al semen le pasa lo mismo: con cada eyaculación, los hombres se acercan a la tumba. Las mujeres que desean matar a sus esposos tienen relaciones sexuales con ellos con mayor frecuencia. (Sobre las ramificaciones de la pérdida de semen entre los atletas, ver Gregor, 1985, p. 145; Monsiváis, 1981, p. 113; Wacquant, 1995a, p. 509). Los poderes sagrados del semen también son invocados por los Meratus Dayaks de Indonesia con un hechizo para detener las balas: "Eres semen. Divinidad blanca. Una gota coagulada. Cerrada con una llave. Hierro fluido. Semen fluido" (citado en Tsing, 1993, p. 77).

\section{El poder}

No es sorprendente que una de las preocupaciones centrales en los primeros estudios de Lewis Henry Morgan donde se documentaba la variación transcultural, fuera la relación cambiante entre parentesco y poder. Fué típico su comentario según el cual "En la familia patriarcal del tipo romano, la autoridad paterna iba más allá de los límites de la razón hasta llegar a un exceso de dominación” (Morgan, 1985, p. 466-467). Aunque existen otros desacuerdos, en la mayoría de los artículos antropológicos sobre la masculinidad hasta la fecha, hay una especie de consenso respecto a la desigualdad; y el por qué y cómo la desigualdad de género puede caracterizar las relaciones entre mujeres y hombres y entre hombres diferentes, en situaciones históricas y culturales diversas. Con el propósito de describir los elementos de la lucha masculina por el poder, y como parte de la búsqueda de la "estructura profunda de la masculinidad”, David Gilmore (1990, p. 106) promovió la noción de que en muchas, si no en la mayoría de las culturas, los hombres por los menos comparten la creencia de que ellos son creados artificialmente mientras que las mujeres nacen naturalmente. Por consiguiente, los hombres deben ponerse a prueba entre sí de maneras que no lo tienen que hacer las mujeres (ver 
también Dwyer, 1978; Herdt, 1987, p. 6; Mead, 1975, p. 103). Estas imágenes transculturales y transhistóricas acerca de los hombres se recogen en trabajos recientes de Bourdieu (1995, 1997) sobre la masculinidad, e.g. cuando afirma que irrespecto de tiempo o espacio, "entre todas las formas de esencialismo [el sexismo] es sin duda el más difícil de erradicar” (p. 103), y cuando declara (1997) que "el acto sexual es por consiguiente representado como un acto de dominación, un acto de posesión, como la 'toma' de la mujer por el hombre”, lo cual supone que las posiciones sexuales son las mismas para todo el mundo en todo momento.

\section{Varones alfa y míticos}

Existe evidencia etnográfica para tales generalizaciones. En la Turquía rural, no solamente se simboliza al Dios creativo como masculino, sino que se considera que los varones humanos son quienes dan la vida en tanto que las mujeres apenas alumbran (Delaney, 1991). Entre los Tswana del siglo diecinueve, mediante el intercambio de ganado "los hombres producían y reproducían la sustancia social de la colectividad -en contraste con la reproducción física hecha por las mujeres, de sus componentes individuales" (Comaroff, 1985, p. 60). El problema estriba no en los análisis de situaciones culturales específicas, sino en el resumen según el cual "los hombres en todo el mundo comparten las mismas nociones” (Gilmore, 1990, p. 109) acerca de los hombres varoniles (activos, creativos), dado que tales nociones se basan en su mayoría en lo que los informantes varones les han dicho a los etnógrafos varones acerca de sí mismos y acerca de las mujeres. Entre los primeros estudios etnográficos sobre salud reproductiva entre los hombres, los mejores son de Viveros (1998), Viveros y Gómez (1998) y Figueroa (1998).

Los escritores que comparten con Lévi-Strauss (1991a) la conclusión según la cual el "surgimiento del pensamiento simbólico debe haber requerido que las mujeres, al igual que las palabras, sean objetos de intercambio”, pocas veces encuentran diferencias culturalmente significativas entre los hombres y entre diferentes clases de masculinidades. En contraste con aquellos paradigmas basados en imágenes relativamente homogéneas de la masculinidad y de hombres todopoderosos, se encuentran los conceptos de masculinidades hegemónicas y subordinadas (o marginales) propuestos por Connell (1987, 1995). Connell busca establecer un mapa comprehensivo de las desigualdades 
de poder, a la vez que intenta dar cuenta de las diversas relaciones entre mujeres y hombres, específicamente de la mediación activa de las mujeres (ver Stephen 1997) y de los hombres en la transformación de las relaciones de género.

Una contribución importante de los estudios antropológicos sobre la masculinidad ha sido la de explorar las percepciones subjetivas de los hombres acerca de ser hombres, donde se incluye la relación de ser hombre con la reivindicación, búsqueda y ejercicio de varias formas de poder sobre otros hombres y sobre las mujeres. Así, estos estudios han servido como complemento de trabajos anteriores sobre el "mito de la dominación masculina" (cf. Leacock, 1981; Rogers, 1975), de los interrogantes acerca del poder informal de las mujeres, y de los aspectos relacionados con el "ser varonil”. Ha sido difícil en el estudio de la masculinidad, documentar la variedad de formas y modos que asumen las relaciones de poder basadas en el género (á la Foucault) sin perder de vista las desigualdades fundamentales entre hombres y mujeres, en muchos contextos donde puede ser difícil discernirlas en el nivel familiar, de pequeña escala. El reconocer la variedad e inclusive la complicidad, no significa dejar de lado la habilidad para distinguir poderes mayores y menores ni presupone aceptar la teoría hidráulica del poder según la cual la ganancia de uno necesariamente implica la pérdida del otro, aunque si exige un marco de referencia histórico claro (ver di Leonardo, 1979; Sacks, 1982).

\section{El nacionalismo, la guerra y la violencia doméstica}

Trabajos recientes e innovadores acerca de la masculinidad y la violencia hacen referencia a las cuestiones del nacionalismo, la guerra y la violencia doméstica. La guerra obviamente existe con anterioridad y por fuera de los contextos nacionalistas, y los lectores interesados en el tema de los hombres y la guerra en sociedades tribales y en otras donde no existe el estado, pueden consultar a Chagnon (1968) para una etnografía sociobiológica clásica sobre la masculinidad y la guerra, así como a Fried, Harris y Murphy (1967) para una vision más general sobre la antropología de la guerra. En cuanto al nacionalismo, sus vínculos con lo varonil en una diversidad de contextos culturales, no podrían ser más claros. Por ejemplo Mosse (1996) documentó las historias asociadas del nacionalismo europeo y la masculinidad. Oliven (1992) analizó los gauchos brasileros y la identidad nacional, Guy (1992) examinó la 
relación histórica entre la sexualidad masculina, la familia y el nacionalismo en Argentina.

En la Creta rural, Herzfeld (1985, p. 25) describió la poniria (astucia baja) como "un atributo emblemático de la virilidad, y por ser la quintaescencia de lo griego, una fuente de orgullo agresivo”, característico de un cierto tipo de virilidad, análogo a lo femenino, en oposición a las formas oficiales masculinas de sabiduría e inteligencia. Greenberg, J. (1989) señaló varias semejanzas en una aldea del sur de México. En su análisis sobre la descripción popular de los muchachos Parsi de la época poscolonial en la India como serviles e impotentes, Luhrmann (1996, p. 132-133) dedujo que este discurso sexualizado referido a las inadecuaciones masculinas representa un desplazamiento de la ansiedad debido a que "entre los Parsis la idea de impotencia está asociada no solamente con los hombres Parsi, sino también con el fin del imperio". De formas muy diversas, otros han establecido conexiones entre la masculinidad, la violencia y el poder formal. En Nueva Guinea, los hombres influenciados por el mensaje colonial según el cual la pobreza allí existente se debía principalmente a la violencia masculina, respondieron según Brison (1995, p. 172), con una ambivalencia nueva acerca del poder o trataron de capitalizar su "rudeza", lo cual en ambos casos sirvió para resaltar el poder y prestigio de los europeos. Para una investigación etnográfica cortante acerca de la masculinidad y los líderes militares en Estados Unidos, ver Cohn (1987). Sobre los aspectos de la masculinidad en el contexto del terrorismo de estado, ver Nordstrom y Martin (1992).

Si el golpear a la esposa se da entre recién casados (Herdt, 1994) o durante el primer embarazo de la mujer (Gutmann, 1998), si se considera que la violencia masculina prevalece históricamente más en ciertas clases que en otras o entre hombres que están perdiendo su poder autoritario sobre las mujeres (Bourgois, 1995; Liendro, 1998; Montoya, 1998), en los documentos antropológicos sobre los hombres, las fuentes de la violencia, cuando no sus consecuencias, muchas veces están sobredeterminadas y subteorizadas excepción hecha de quienes promueven la importancia de los factores biológico-hormonales en el comportamiento humano, tales como Konner (1982, p. 111) quien sostuvo que "el caso más fuerte a favor de las diferencias de género (regidas por la biología) se encuentra en el campo del comportamiento agresivo". Las teorías correspondientes que se apoyan en factores político-económicos, raciales, de género y culturales son tristemente inadecuadas en la literatura antropológica sobre los hombres y la violencia. 
Los antropólogos varones tampoco han sido lo suficientemente activos en lo que se refiere a la investigación de los temas más importantes y difíciles relacionados con la violencia de género tales como la violación y el maltrato a las mujeres. Para una colección única sobre el maltrato femenino, ver Counts, Brown y Campbell (1992). Aunque Gregor (1985) y otros han discutido el peligro de la violación en las sociedades tribales, a excepción de los trabajos de Bourgois (1995) y Sanday (1990) sobre la violación en los Estados Unidos contemporáneos, son pocos los esfuerzos serios hechos por los antropólogos para documentar y contextualizar esta forma de maltrato masculino contra las mujeres en las sociedades modernas. [El informe de Malinowski (1983) sobre yausa -los "asaltos orgiásticos" de las mujeres Trobriand mediante los cuales ellas violaban grupalmente a un hombre- sigue siendo poco usual en los anales etnográficos].

\section{Las mujeres y la masculinidad}

Para contrarestar las décadas durante las cuales los antropólogos varones entrevistaban y describían casi exclusivamente a informantes varones, las antropólogas feministas hicieron mucho énfasis a principios de los años de 1970 en las mujeres y en los denominados "mundos de las mujeres". En buena parte se trataba de "descubrir" a las mujeres quienes habían estado tan notoriamente ausentes (o “desaparecidas”) de las etnografías anteriores. Tan sólo hacia los años de 1980 los hombres empezaron a explorar en forma sistemática a los hombres como personas con género y que otorgan género. Pero irónicamente, la mayor parte de los estudios etnográficos sobre la masculinidad han hecho uso insuficiente de las contribuciones feministas a nuestros conocimientos sobre la sexualidad y el género y no han participado mucho en los importantes debates de este discurso. En parte, ello ilustra lo que Lutz (1995) denomina la "masculinización de la teoría", en este caso mediante la evasión de lo que se considera de poco valor teórico. [Ver por ejemplo, la censura de Gilmore (1990, p. 23, 166) sobre los “marxistas doctrinarios” y las “feministas radicales”].

La forma de incorporar las opiniones y experiencias de las mujeres respecto a los hombres y la masculinidad es de gran importancia. Algunos antropólogos han planteado que como hombres, están muy limitados en su 
capacidad para trabajar con mujeres. (Para versiones diferentes al respecto ver Brandes, 1987; Gilmore, 1990, 1991; Gregory, 1984; Herdt; Stoller, 1990; Keesing, 1982; Streicker, 1995). Gutmann (1999) sostiene que las investigaciones etnográficas sobre los hombres y la masculinidad deben incluir las ideas que las mujeres tiene sobre los hombres y sus experiencias con ellos. Más que la simple afirmación estadística según la cual al aumentar el tamaño de la muestra se logrará aumentar nuestra comprensión del sujeto de estudio, y más que ofrecer un suplemento al trabajo etnográfico con hombres sobre la masculinidad a través de la inclusión de las voces y experiencias femeninas, la cuestión vigente sigue siendo la relacionada con el hecho de que las masculinidades se desarrollan y transforman y que tienen poco significado si no se relacionan con las mujeres y las identidades y prácticas femeninas en toda su diversidad y complejidad correspondientes.

Algunos antropólogos han escrito sobre las ansiedades de castración de los hombres (e.g. Murphy; Murphy, 1985) y sobre las intimidades entre madre e hijo (cf. Gregor, 1985; Spiro, 1982). Ubicándose en un marco de referencia lacaniano, Allison (1994, p. 150) señaló refiriéndose a los clubes de sexo de Tokyo, que" lo que los hombres dicen que necesitan, lo que piensan estar haciendo, y justifiquen como necesario 'para el trabajo' ... se lleva a cabo en forma simbólica y ritual a través de las mujeres y de la sexualidad que ellas representan’. Bloch (1986, p. 103-104) argumentó que la ambigüedad central de los ritos de circuncisión masculina de los Merina tenía que ver con que se identificaba a las mujeres tanto con lo salvaje como con la descendencia ancestral. Puede plantearse que desde Lévi-Strauss [e.g. O cru e o cozido (1991b)], todo esto ha sido obvio para la antropología: Al trabajar dentro de este marco de referencia Sherry Ortner (1979) construyó su modelo naturaleza/cultura en el cual se definía explícitamente a los hombres en relación con las mujeres. No obstante, este modelo está basado en la noción según la cual aunque las mujeres pueden “controlar” a los hijos varones, entre los adultos lo que prevalece es que los hombres culturalmente dominan a las mujeres.

Así, a determinado nivel, el tema de la influencia de las mujeres sobre los hombres y la masculinidad ha sido extensamente tratado aunque aún no sea este el caso en la literatura referida al establecimiento de vínculos entre madre e hijo, al conflicto edípico, y a la separación madre-hijo. El paso a seguir es el de vincular estos estudios y preocupaciones aparentemente más de 
tipo sicológico con los interrogantes políticos sobre el poder y la desigualdad. Necesitamos prestar atención no solamente a la autoridad de las madres sobre los hijos varones sino también a la influencia de las mujeres sobre los adultos varones. El estudio de Stern (1995) sobre la época colonial tardía en México es ejemplar en su análisis acerca de la mediación y las aspiraciones de las mujeres en la promoción de " cambios en las principales convenciones sociales relacionadas con el género” y del patriarcado dentro de un contexto de una nueva política económica del crecimiento y la industrialización.

El tema recurrente en muchos documentos antropológicos sobre la masculinidad sostiene que "según los nativos", los hombres se hacen en tanto que las mujeres nacen. La concienzuda crítica de esta concepción que se encuentra en MacCormack y Strathern (1980) ha sido muy influyente en la antropología feminista, pero desafortunadamente muy poco tenida en cuenta por los antropólogos para quienes las mujeres son irrelevantes en las construcciones de la masculinidad. No obstante, vale la pena preguntarse si no existen sesgos en las narraciones de algunos etnógrafos. Esto es un asunto metodológico, y más aún, conceptual, porque aunque es un error asumir que existe demasiada similitud entre contextos culturales, las conclusiones según las cuales es imposible que un etnógrafo varón pueda recoger información útil sobre las mujeres, y mucho menos de las mujeres sobre los hombres, parecen ameritar mayor atención. Aunque las mujeres y los hombres no se encuentren en presencia del otro durante los rituales, para dar un ejemplo, los hombres y las mujeres si interactúan regularmente durante otros momentos, y afectan profundamente sus vidas e identidades mutuas. No debemos confundir los roles y las definiciones formales con la vida diaria.

Se han logrado avances importantes en el estudio de las mujeres en diversos contextos culturales. Los estudios correspondientes de la masculinidad están aún muy rezagados. Ello no significa que las etnografías sobre los hombres deban ser consideradas, entendidas o utilizadas principalmente como un complemento a los estudios de las mujeres. Más bien, deben ser desarrolladas y nutridas como algo integral para la comprensión de la relación ambigua entre diferencias y similitudes, igualdades y desigualdades de género múltiple. Es el mismo caso de lo que sucede con el estudio de la etnicidad: nunca se puede estudiar un género sin estudiar los otros. 


\section{Puntos recientes de convergencia}

\section{Los ritos de iniciación masculina}

En su discusión sobre los ritos de paso masculinos en Nueva Guinea, Keesing (1982) encuentra paralelos entre esa área y la Amazonia: (a) el énfasis puesto en el crecimiento creado versus el natural de los muchachos para convertirse en hombres, (b) lo que los hombres pueden producir -de maneras que no lo pueden hacer las mujeres- son hombres. Lo que hace la iniciación según Keesing (1982, p. 35) es "dramatizar el cambio de status a través del renacimiento simbólico- a la vez que incide directa y drásticamente a nivel sicológico, sobre los vínculos con las mujeres y su mundo, los cuales deben ser abandonados por los novicios". El debate continua respecto a si los ritos de iniciación representan más una ruptura simbólica con las madres y las mujeres en general, o si están más relacionados con la pubertad y las etapas fisiológicas de la maduración; tanto la mutilación corporal masculina como la seclusión de los varones de las mujeres se destacan en muchos registros de los ritos de iniciación. (Ver también Herdt, 1982; Newman; Boyd, 1982; Whiting; Kluckhohn; Anthony, 1958).

De nuevo, desde Nueva Guinea, de la Amazonia hasta Madagascar, las mujeres parecen ocupar un lugar central tanto en los eventos de iniciación como en los análisis explicativos de su significado. Comaroff (1985, p. 114) describió cómo en los ritos de iniciación de los Tswana de la precolonia, se proyecta al hombre como "ser humano hábil" y a la mujer como "socializada en forma incompleta”. Godelier (1986) informó que entre los Baruya "se requieren diez años... para separar a un niño varón de su madre”, en tanto que "se necesitan menos de dos semanas para convertir a una adolescente en una joven lista para el matrimonio y para tener hijos". Al referirse a las ceremonias de circuncisión entre los Merina de Magadascar, Bloch (1986, p. 60) señaló que "la representación negativa de la femineidad es particularmente destacada”. No obstante en otra parte, Bloch (1987, p. 324-325) escribió sobre "la naturaleza sistemáticamente contradictoria de las representaciones de las mujeres” entre los Merina (énfasis en el original). Tan importante comprensión de la contradicción y la indeterminación está frecuentemente ausente de las descripciones de las semblanzas y sentido de los ritos de iniciación 
masculinos, aunque algunos como Dundes (1976) han escrito acerca del género ambivalente de los varones iniciados.

\section{El machismo}

Los hombres en México, en América Latina, y por supuesto en todos los países de habla hispana han sido frecuentemente caracterizados uniformemente como machos por los antropólogos, otros académicos y periodistas. A pesar de que los términos macho, en su acepción moderna, y machismo tienen una historia de pocas palabras, muchos escritores de todo el mundo se han esforzado por descubrir un machismo omnipresente, virulento y "típicamente latino” entre los hombres de estas regiones (ver Viveros, 1997; Valdés; Olavarría, 1997, 1998, Fuller, 1997). En los años de 1990 se ha dado una verdadera explosión en el trabajo etnográfico y áreas relacionadas respecto al machismo (ver Baca-Zinn, 1982; Bolton, 1979; Gilmore; Gilmore, 1979; y más recientemente, Brusco, 1995; Carrier, 1995; de Barbieri, 1990; Gutmann, 1998; Lancaster, 1992; Leiner, 1994; Limón, 1994; Lumsden, 1996; Mirande, 1997; Murray, 1995; Parker, 1994; Ramírez, 1993).

La aseveración central de Brusco (1995) por ejemplo, plantea que el protestantismo evangélico en Colombia ha liberado a las mujeres porque ha “domesticado” a los hombres: los esposos y padres evangélicos evitan el machismo "público" -las borracheras, la violencia y el adulterio- y regresan a sus responsabilidades familiares. Ramírez (1993, p. 13) señaló que la expresión “machismo” no se utiliza en las áreas de clase obrera por él estudiadas en Puerto Rico, sin embargo se usa corrientemente en los círculos académicos y feministas de la isla. Lancaster (1992, p. 237) registró que son las relaciones específicas y desiguales entre hombres y mujeres las que en última instancia “afianzan” el sistema del machismo en general en Nicaragua. Las mujeres pueden ser parte permanente de las vidas de los hombres, pero no entran a ser parte de la ecuación de la masculinidad por razones básicas de la corporalidad.

\section{Conclusiones}

En cualquier discusión sobre la masculinidad existen problemas potenciales, especialmente si el tema se reduce a la posesión de genitales masculinos 
o peor aún si se considera que es “sólo para hombres”. De muchas maneras arbitraria y artificial, esta revisión tiene la intención de contrarestar tal tipologización. Confío en que la lectura de este ensayo no haya sido hecha como un intento por representar el "turno de los hombres" en las mesas académicas donde se indaga sobre el género. Más bien, mi propósito ha sido el de describir los estudios de los hombres como hombres dentro del contexto de un rompecabezas multigénero.

Los antropólogos que tratan diferentes temas reconocerán que en muchos trabajos se da por hecho la naturaleza de los hombres y la masculinidad. Una rápida ojeada a los índices de la mayoría de las etnografías muestra que las "mujeres" existen como categoría en tanto que los "hombres" raramente aparecen listados. La masculinidad o se ignora o se considera que es la norma, de forma tal que el hacer un inventario por separado es innecesario. Así que, aquí también "género" con frecuencia quiere decir mujeres y no hombres.

"En los asuntos más delicados, el etnógrafo se ve obligado en gran medida a depender de los rumores”, afirmó Malinowski (1983, p. 283), y con contadas excepciones, la situación no ha cambiado desde entonces. ¿Cuál debe ser nuestra comprensión de los hombres Arapesh "afeminados” quienes paternan a sus hijos como si fueran madres? ¿Cuál es la razón para que los hijras de la India traten de lograr una terminación permanente a su búsqueda de la "castración”? ¿Cómo y por qué los hombres que se visten coquetamente usando ropa del sexo opuesto en Nicaragua (ver Lancaster, 1997b) hacen exhibición de "feminidad"? Estos son los interrogantes que constituyen la materialidad corporal y las prácticas de hombres que se definen a sí mismos y son definidos por otros, simplemente como personas que no son mujeres.

Entre los modos de desempeño con los cuales se resalta la virilidad en Creta -la facilidad para la palabra, el canto, el baile y el abigeato de ovejas (ver Herzfeld, 1985, p. 124) - y el intento de crear obstáculos modernos en el logro del status de varón (Gilmore 1990, p. 221), se encuentra una variedad de cualidades y caracterizaciones que los antropólogos han denominado masculinas y varoniles. En contradicción con la afirmación según la cual los hombres se hacen mientras las mujeres nacen (así sea de acuerdo al "punto de vista de los nativos”) está la afirmación de acuerdo a la cual los hombres son los defensores de la "naturaleza” y del "orden natural de las cosas", en tanto que las mujeres son quienes instigan a favor del cambio en las relaciones de género y muchas otras cosas. Ello forma parte de lo que Peletz (1996, p. 294) 
denomina "la reestructuración histórica de los roles masculinos", en la medida en que las contradicciones, las desigualdades y las ambigüedades en las relaciones, ideologías y prácticas de género en todas sus múltiples facetas y manifestaciones demuestran ser parte central del proceso de transformaciones sociales de género.

\section{Agradecimientos}

Mis agradecimientos para Stanley Brandes, Daniel Cazés, Lawrence Cohen, Micaela di Leonardo, Norma Fuller, Michael Herzfeld, Benno de Keijzer, Louise Lamphere, Roger Lancaster, Ondina Fachel Leal, José Olavarría, Nancy Scheper-Hughes, Lynn Stephen, Teresa Valdés y Mara Viveros por sus comentarios sobre este ensayo y/o discusiones sobre la masculinidad, y por la bendición de Gayle Rubin quien me permitió hacer eco de su título anterior, el cual a su vez proviene de Emma Goldman. Elaboré este trabajo con el apoyo de una beca postdoctoral del Instituto Nacional de Salud administrada por el Centro de Investigación Preventiva y la Escuela de Salud Pública, Universidad de California, Berkeley. Traducción autorizada de Annual Review of Anthropology, vol. 26, 1997. Todos los derechos reservados por Annual Reviews (http://annualreviews.org).

(Traduzido do inglês por Patricia Prieto)

\section{Referencias}

ALLISON, A. Nightwork: sexuality, pleasure, and corporate masculinity in a Tokyo hostess club. Chicago: University of Chicago Press, 1994.

ALMAGUER, T. Chicano men: a cartography of homosexual identity and behavior. Diferences, v. 3, n. 2, p. 75-100, 1991.

ALTER, J. S. The wrestler's body: identity and ideology in North India. Berkeley: University of California Press, 1992.

ARDENER, E. The voice of prophecy and other essays. London: Basil Blackwell, 1989. 
BACA-ZINN, M. Chicano men and masculinity. Journal of Ethnic Studies, v. 10, n. 2, p. 29-44, 1982.

BATTAGLIA, D. "We feed our father": paternal nurture among the Sabarl of Papua New Guinea. American Ethnologist, v. 12, n. 3, p. 427-441, 1985.

BENEDICT, R. Patterns of culture. Boston: Houghton Mifflin, 1934.

BLOCH, M. From blessing to violence: history and ideology in the circumcision ritual of the Merina of Madagascar. Cambridge: Cambridge University Press, 1986.

BLOCH, M. Descent and sources of contradiction in representations of women and kinship. In: COLLIER, J. F.; YANAGISAKO, S. J. (Ed.). Gender and kinship: essays toward a unified analysis. Stanford: Stanford University Press, 1987. p. 324-337.

BLY, R. Hombres de hierro. Buenos Aires: Planeta, 1992.

BOLTON, R. Machismo in motion: the ethos of Peruvian truckers. Ethos, v. 7, n. 4, p. 312-342, 1979.

BOURDIEU, P. Le sens pratique. Paris: Editions de Minuit, 1980.

BOURDIEU, P. A dominação masculina. Educação e Realidade, v. 20, n. 2, p. 133-184, 1995.

BOURDIEU, P. Masculine domination revisited. Berkeley Journal of Sociology, Quito: Ediciones ABYA-YALA, p. 9-108, 1997.

BOURGOIS, P. In search of respect: selling crack in El Barrio. Cambridge: Cambridge University Press, 1995.

BOWDEN, R. Art and gender ideology in the Sepik. Man, v. 19, n. 3, p. 445458, 1984.

BRANA-SHUTE, G. On the corner: male social life in a Paramaribo Creole neighborhood. Prospect Heights: Waveland, 1979. 
BRANDES, S. Sex roles and anthropological research in rural Andalusia. Women's Studies, n. 13, p. 357-372, 1987.

BRANDES, S. Metáforas de la masculinidad: sexo y estatus en el folklore andaluz. Madrid: Taurus, 1991.

BRISON, K. Changing constructions of masculinity in a Sepik society. Ethnology, v. 34, n. 3, p. 155-175, 1995.

BROUDE, G. J. Protest masculinity: a further look at the causes and the concept. Ethos, v. 18, n. 1, p. 103-122, 1990.

BRUSCO, E. E. The reformation of machismo: evangelical conversion and gender in Columbia. Austin: University of Texas Press, 1995.

CARRIER, J. M. De los otros: intimacy and homosexuality among Mexican men. New York: Columbia University Press, 1995.

CASTELAIN-MEUNIER, C. Les hommes, aujourd'hui: virilite et identité. Paris: Acropole, 1988.

CATH, S. H.; GURWITT, A.; GUNSBERG, L. (Ed.). Fathers and their families. Hillsdale: Analytic Press, 1989.

CHAGNON, N. A. Yanomamo: the fierce people. New York: Holt, Rinehart and Winston, 1968.

CHODOROW, N. J. Femininities, masculinities, sexualities: Freud and beyond. Lexington: University of Kentucky Press, 1994.

COHEN, L. The pleasures of castration: the postoperative status of hijras, jankhas, and academics”. In: ABRAMSON, R. R.; PINKERTON, S. D. (Ed.). Sexual nature, sexual culture. Chicago: University of Chicago Press, 1995a. p. 276-304.

COHEN, L. Holi in Banaras and the Mahaland of modernity. Gay and Lesbian Quarterly, n. 2, p. 399-424, 1995b. 
COHN, C. Sex and death in the rational world of defense intellectuals. Signs, v. 12, n. 4, p. 687-718, 1987.

COMAROFF, J. Body of power, spirit of resistance: the culture and history of a South African people. Chicago: University of Chicago Press, 1985.

CONNELL, R. W. Gender and power: society, the person and sexual politics. Cambridge: Polity Press, 1987.

CONNELL, R. W. Masculinities. Berkeley: University of California Press, 1995.

COUNIHAN, C. Transvestism and gender in a Sardinian Carnival. Anthropology, n. 9, p. 11-24, 1985.

COUNTS, D. A.; BROWN, J. K.; CAMPBELL, J. C. (Ed.). Sanctions and sanctuary: cultural perspectives on the beating of wives. Boulder: Westview, 1992.

COWAN, J. K. Dance and the body politic in Northern Greece. Princeton: Princeton University Press, 1990.

DE BARBIERI, T. Sobre géneros, prácticas y valores: notas acerca de posibles erosiones del machismo en México. In: SÁIZ, J. M. R. (Org.). Normas y prácticas: morales y cívicas en la vida cotidiana. México: Universidad Nacional Autónoma de México, 1990. p. 83-106.

DELANEY, C. The seed and the soil: gender and cosmology in Turkish village society. Berkeley: University of California Press, 1991.

DI LEONARDO, M. Methodology and misinterpretation of women's status in kinship studies: a case study of Goodenough and the definition of marriage. American Ethnologist, v. 6, n. 4, p. 627-637, 1979.

DUNDES, A. A psychoanalytic study of the bullroarer. Man, n. 11, p. 220238, 1976. 
DUNDES, A. Into the endzone for a touchdown: a psychoanalytic consideration of American football. Western Folklore, n. 37, p. 75-88, 1978.

DUNEIER, M. Slim's table: race, respectability, and masculinity. Chicago: University of Chicago Press, 1992.

DURKHEIM, E. A divisão do trabalho social. Lisboa: Presença, 1984.

DWYER, O. Images and self-images: male and female in Morocco. New York: Columbia University Press, 1978.

ELLISTON, D. A. Erotic anthropology: "ritualized homosexuality" in Melanesia and beyond. American Ethnologist, v. 22, n. 4, p. 848-867, 1995.

EVANS-PRITCHARD, E. E. (Comp.). Man and woman among the Azande. London: Faber and Faber, 1974.

FANON, F. Black skin, white masks. New York: Grove, 1967.

FIGUEROA, J. G. Algunas propuestas analíticas para interpretar la presencia de los varones en los procesos de salud reproductiva. In: VALDÉS, T.; OLAVARRÍA, J. (Org.). Masculinidades y equidad de género en América Latina. Santiago de Chile: FLACSO, 1998. p. 175-198.

FOUCAULT, M. História da sexualidade: vol. 1. Rio de Janeiro: Graal, 1977.

FOUCAULT, M. Herculine Barbin: being the recently discovered memoirs of a nineteenth-century French hermaphrodite. New York: Pantheon, 1980.

FRIED, M.; HARRIS, M.; MURPHY, R. (Ed.). War: the anthropology of armed conflict and aggression. New York: Natural History, 1967.

FRIEDL, E. Women and men: an anthropologist's view. Prospect Heights: Waveland Press, 1984.

FULLER, N. Identidades masculinas: varones de clase media en el Perú. Lima: Fondo Editorial de la Pontificia Universidad Católica del Perú, 1997. 
FULLER, N. La constitución social de la identidad de género entre varones urbanos del Perú. In: VALDÉS, T.; OLAVARRÍA, J. (Org.). Masculinidades y equidad de género en América Latina. Santiago de Chile: FLACSO, 1998. p. 56-68.

GILMORE, D. D. Manhood in the making: cultural concepts of masculinity. New Haven: Yale University Press, 1990.

GILMORE, D. D. Commodity, comity, community: male exchange in rural Andalusia. Ethnology, v. 30, n. 1, p. 17-30, 1991.

GILMORE, M. M.; GILMORE, D. D. Machismo: a psychodynamic approach. Journal of Psychoanalytic Anthropology, v. 2, n. 3, p. 281-300, 1979.

GINSBURG, F. The "word-made" flesh: the disembodiment of gender in the abortion debate. In: GINSBURG, F.; TSING, A. L. (Ed.). Uncertain terms: negotiating gender in American culture. Boston: Beacon, 1990. p. 59-75.

GODELIER, M. La formación de grandes hombres: poder y dominación masculina entre los baruya de New Guinea. Madrid: Akal Universitaria, 1986.

GODELIER, M.; STRATHERN, M. (Ed.). Big men and great men: personifications of power in Melanesia. Cambridge: Cambridge University Press, 1991.

GREENBERG, D. F. The construction of homosexuality. Chicago: University of Chicago Press, 1988.

GREENBERG, J. Blood ties: life and violence in rural Mexico. Tucson: University of Arizona Press, 1989.

GREGOR, T. Anxious pleasures: the sexual life of an Amazonian people. Chicago: University of Chicago Press, 1985.

GREGORY, J. R. The myth of the male ethnographer and the woman's world. American Anthropologist, n. 86, p. 316-327, 1984.

GUTMANN, M. C. Ser hombre de verdad en la Ciudad de México: ni macho ni mandilón. México: El Colegio de México: Editorial Paidós, 1998. 
GUTMANN, M. C. Las fronteras corporales de género: las mujeres en la negociación de la masculinidad. In: VIVEROS, M.; GARAY, G. (Org.). Cuerpo, diferencias y desigualdades. Bogotá: Universidad Nacional de Colombia, 1999. p. 105-123.

GUY, D. J. Sex and danger in Buenos Aires: prostitution, family, and nation in Argentina. Lincoln: University of Nebraska Press, 1992.

HERDT, G. (Ed.). Rituals of manhood: male initiation in Papua New Guinea. Berkeley: University of California Press, 1982.

HERDT, G. The Sambia: ritual and gender in New Guinea. Fort Worth: Holt, Rinehart \& Winston, 1987.

HERDT, G. (Ed.). Ritualized homosexuality in Melanesia. Berkeley: University of California Press, 1993.

HERDT, G. Guardians of the flutes: idioms of masculinity. Chicago: University of Chicago Press, 1994.

HERDT, G.; STOLLER, R. J. Intimate communications: erotics and the study of culture. New York: Columbia University Press, 1990.

HERMAN, E. The romance of American psychology: political culture in the age of experts. Berkeley: University of California Press, 1995.

HERZFELD, M. The poetics of manhood: contest and identity in a Cretan mountain village. Princeton: Princeton University Press, 1985.

HERZFELD, M. 'As in your own house”: hospitality, ethnography, and the stereotype of Mediterranean society. In: GILMORE, D. D. (Ed.). Honor and shame and the unity of the Mediterranean. Washington: American Anthropological Association, 1987. p. 75-89.

HERZFELD, M. Silence, submission, and subversion: toward a poetics of womanhood. In: LOIZOS, P.; PAPATAXIARCHIS, E. (Ed.). Contested identities: gender and kinship in modern Greece. Princeton: Princeton University Press, 1991. p. 79-97. 
HEWLETT, B. S. Intimate fathers: the nature and context of Aka Pygmy paternal infant care. Ann Arbor: University of Michigan Press, 1991.

HOLLOS, M.; LEIS, P. Becoming Nigerian in Ijo society. New Brunswick: Rutgers University Press, 1989.

JACOBS, S. E.; THOMAS, W.; LANG, S. (Ed.). Two-spirit people: Native American gender identity, sexuality and spirituality. Urbana: University of Illinois Press, 1997.

JARDIM, D. Espaço social e auto-segração entre homens: gostos, sonoridades e masculinidade. Cadernos de Antropologia, Porto Alegre: UFRGS, n. 7, p. 29-42, 1992.

KATZ, J. The invention of heterosexuality. Socialist Review, n. 1, p. 7-34, 1990.

KEESING, R. M. Introduction. In: HERDT, G. (Ed.). Rituals of manhood: male initiation in Papua New Guinea. Berkeley: University of California Press, 1982. p. 1-43.

KNAUSS, P. The persistance of patriarchy: class, gender, and ideology in twentieth century Algeria. New York: Praeger, 1987.

KOHRMAN, M. Motorcycles for the disabled: power, mobility, and the transformation of experience in urban China. 1997. Manuscrito.

KONNER, M. The tangled wing: biological constraints on the human spirit. New York: Harper, 1982.

LANCASTER, R. N. Life is hard: machismo, danger, and the intimacy of power in Nicaragua. Berkeley: University of California Press, 1992.

LANCASTER, R. N. On homosexualities in Latin America (and other places). American Ethnologist, v. 24, n. 1, p. 193-202, 1997 a.

LANCASTER, R. N. Guto's performance: notes on the transvestism of everyday life. In: BALDERSTON, D.; GUY, D. J. (Ed.). Sex and sexuality in Latin America. New York: New York University Press, 1997b. 
LANCASTER, R. N. The queer body. Berkeley: University of California Press, 1998.

LAQUEUR, T. La construcción del sexo: cuerpo y género desde los griegos hasta Freud. Madrid: Cátedra, 1994.

LEACOCK, E. Myths of male dominance. New York: Monthly Review, 1981.

LEAL, O. F. (Org.). Cadernos de Antropologia. Cultura e identidade masculina. Porto Alegre: UFRGS, n. 7, 1992.

LEE, R. B. What hunters do for a living, or, how to make out on scare resources. In: LEE, R. B.; DEVORE, I. (Ed.). Man the hunter. Chicago: Aldine, 1968. p. $30-48$.

LEINER, M. Sexual politics in Cuba: machismo, homosexuality, and AIDS. Boulder: Westview, 1994.

LÉVI-STRAUSS, C. Las estructuras elementales del parentesco. Barcelona: Paidós, 1991a.

LÉVI-STRAUSS, C. O cru e o cozido: mitológicas. São Paulo: Brasiliense, 1991b.

LEWGOY, B. Os cafés na vida urbana de Porto Alegre (1920-1940): as transformações em um espaço de sociabilidade masculino. Cadernos de Antropologia, Porto Alegre: UFRGS, n. 7, p. 61-80, 1992.

LEWIS, O. Tepoztlán: un pueblo de México. México: Joaquín Mortiz, 1968.

LIENDRO, E. Masculinidades y violencia desde un programa de acción en México. In: VALDÉS, T.; OLAVARRÍA, J. (Org.). Masculinidades y equidad de género en América Latina. Santiago de Chile: FLACSO, 1998. p. 130-136.

LIMÓN, J. Dancing with the Devil: society and cultural poetics in MexicanAmerican South Texas. Madison: University of Wisconsin Press, 1994.

LOMNITZ, L. A. Cómo sobreviven los marginados. México: Siglo Veintiuno, 1975. 
LOMNITZ, L. A.; PÉREZ-LIZAUR, M. Una familia de la élite mexicana, 1820-1980. México: Alianza, 1993.

LUHRMANN, T. M. The good Parsi: the fate of a colonial elite in a postcolonial society. Cambridge: Harvard University Press, 1996.

LUMSDEN, I. Machos, maricones, and gays: Cuba and homosexuality. Philadelphia: Temple University Press, 1996.

LUTZ, C. The gender of theory. In: BEHAR, R.; GORDON, D. A. (Ed.). Women writing culture. Berkeley: University of California Press, 1995. p. 249-266.

MACCORMACK, C.; STRATHERN, M. (Ed.). Nature, culture and gender. Cambridge: Cambridge University Press, 1980.

MAGEO, J. M. Male transvestism and cultural change in Samoa. American Ethnologist, v. 19, n. 3, p. 443-459, 1992.

MALINOWSKI, B. Sexo e repressão na sociedade selvagem. Petrópolis: Vozes, 1973.

MALINOWSKI, B. A vida sexual dos selvagens. Rio de Janeiro: Francisco Alves, 1983.

MARSHALL, M. Weekend warriors: alcohol in a Micronesian culture. Palo Alto: Mayfield, 1979.

MEAD, M. Male and female: a study of the sexes in a changing world. New York: William Morrow, 1975.

MEAD, M. Sexo y temperamento en tres sociedades primitivas. Barcelona: Paidós, 1982.

MERLEAU-PONTY, M. Phenomenology of perception. London: Routledge and Kegan Paul, 1962.

MERNISSI, F. Beyond the veil: male-female dynamics in a modern Muslim society. Bloomington: University of Indiana Press, 1987. 
MIRANDE, A. Hombres y machos: masculinity and Latino culture. Boulder: Westview, 1997.

MONSIVÁIS, C. Escenas de pudor y liviandad. México: Grijalbo, 1981.

MONTOYA, O. Nadando contra corriente: buscando pistas para prevenir la violencia masculina en las relaciones de pareja. Managua: Puntos de Encuentro, 1998.

MOORE, H. L. Feminismo y antropología. Madrid: Cátedra, 1991.

MORGAN, L. H. Ancient society. Tucson: University of Arizona Press, 1985.

MOSSE, G. L. The image of man: the creation of modern masculinity. New York: Oxford University Press, 1996.

MURPHY, Y.; MURPHY, R. F. Women of the forest. New York: Columbia University Press, 1985.

MURRAY, S. O. Latin American male homosexualities. Albuquerque: University of New Mexico Press, 1995.

NANDA, S. Neither man nor woman: the hijras of India. Belmont: Wadsworth, 1990.

NEWMAN, P. L.; BOYD, D. J. The making of men: ritual and meaning in Awa male initiation. In: HERDT, G. (Ed.). Rituals of manhood: male initiation in Papua New Guinea. Berkeley: University of California Press, 1982, p. 239285.

NEWTON, E. Mother camp: female impersonators in America. Englewood Cliffs: Prentice-Hall, 1972.

NORDSTROM, C.; MARTIN, J. (Ed.). The paths to domination, resistance, and terror. Berkeley: University of California Press, 1992.

OLIVEN, R. A parte e o todo: a diversidade cultural no Brasil-Nação. Petrópolis: Vozes, 1992. 
ORTNER, S. B. Está a mulher para o homem assim como a natureza para a cultura?. In: ROSALDO, M.; LAMPHERE, L. (Org.). A mulher, a cultura e a sociedade. São Paulo: Paz e Terra, 1979.

ORTNER, S. B.; WHITEHEAD, H. Accounting for sexual meanings. In: ORTNER, S. B.; WHITEHEAD, H. (Ed.). Sexual meanings: the cultural construction of gender and sexuality. Cambridge: Cambridge University Press, 1981. p. 1-27.

PAIGE, K. E.; PAIGE, J. M. The politics of reproductive ritual. Berkeley: University of California Press, 1981.

PAPATAXIARCHIS, E. Friends of the heart: male commensal solidarity, gender, and kinship in Aegean Greece. In: LOIZOS, P.; PAPATAXIARCHIS, E. (Ed.). Contested identities: gender and kinship in modern Greece. Princeton: Princeton University Press, 1991. p. 156-179.

PARKER, R. G. A construção da solidariedade: AIDS, sexualidade e política no Brasil. Rio de Janeiro: Relume-Dumará, 1994.

PARKER, R. G.; GAGNON, J. H. (Ed.). Conceiving sexuality: approaches to sex research in a postmodern world. New York: Routledge, 1995.

PARKER, S.; PARKER, H. Male gender identity in the Israeli kibbutz: reflections on "protest masculinity”. Ethos, v. 20, n. 3, p. 340-357, 1992.

PARKER, A. et al. (Ed.). Nationalisms and sexualities. New York: Routledge, 1992.

PARSONS, T.; BALES, R. F. Family, socialization and interaction process. New York: Free Press, 1955.

PELETZ, M. G. Reason and passion: representations of gender in a Malay society. Berkeley: University of California Press, 1996.

POOLE, F. J. P. The ritual forging of identity: aspects of person and self in Bimin-Kuskusmin male initiation. In: HERDT, G. (Ed.). Rituals of manhood: male initiation in Papua New Guinea. Berkeley: University of California Press, 1982. p. 99-154. 
RAMÍREZ, R. L. Dime capitán: reflexiones sobre la masculinidad. Río Piedras: Ediciones Huracán, 1993.

READ, K. E. Nama cult of the Central Highlands, New Guinea. Oceana, v. 23, n. 1, p. 1-25, 1952.

ROBERTSON, J. The politics of androgyny in Japan: sexuality and subversion in the theater and beyond. American Ethnologist, v. 19, n. 2, p. 419-442, 1992.

ROGERS, S. C. Female forms of power and the myth of male dominance: a model of female/male interaction in peasant society. American Ethnologist, v. 2, n. 4, p. 727-755, 1975.

ROSCOE, W. The Zuni man-woman. Albuquerque: University of New Mexico Press, 1991.

RUBIN, G. El tráfico en las mujeres: notas acerca de la "economía política" del sexo. New Antropología, n. 8, p. 95-145, 1986.

RUBIN, G. Thinking sex: notes for a radical theory of the politics of sexuality. In: ABELOVE, H. et al. (Ed.). The lesbian and gay studies reader. New York: Routledge, 1993. p. 3-44.

RUBIN, G. Sexual traffic: interview. Differences, v. 6, n. 2-3, p. 62-99, 1994.

SACKS, K. Sisters and wives: the past and future of sexual inequality. Urbana: University of Illinois Press, 1982.

SANDAY, P. R. Fraternity gang rape: sex, brotherhood, and privilege on campus. New York: New York University Press, 1990.

SCHEPER-HUGHES, N. Saints, scholars, and schizophrenics: mental illness in rural Ireland. Berkeley: University of California Press, 1979.

SCHEPER-HUGHES, N. Death without weeping: the violence of everyday life in Brazil. Berkeley: University of California Press, 1992.

SCHWALBE, M. Unlocking the iron cage: the men's movement, gender, politics, and American culture. New York: Oxford University Press, 1996. 
SEDGWICK, E. K. Between men: English literature and male homosocial desire. New York: Columbia University Press, 1985.

SMITH, R. The negro family in British Guiana: family structure and social status in the villages. London: Routledge and Kegan Paul, 1956.

SPIRO, M. E. Oedipus in the Trobriands. Chicago: University of Chicago Press, 1982.

STACK, C. All our kin: strategies for survival in a black community. New York: Harper and Row, 1974.

STERN, S. J. The secret history of gender: women, men, and power in late colonial Mexico. Chapel Hill: University of North Carolina Press, 1995.

STOLER, A. L. Carnal knowledge and imperial power: gender, race, and morality in colonial Asia. In: DI LEONARDO, M. (Ed.). Gender at the crossroads of knowledge: feminist anthropology in the postmodern era. Berkeley: University of California Press, 1991. p. 51-101.

STRATHERN, M. Gender of the gift: problems with women and problems with society in Melanesia. Berkeley: University of California Press, 1988.

STREICKER, J. Policing boundaries: race, class, and gender in Cartagena, Colombia. American Ethnologist, v. 22, n. 1, p. 54-74, 1995.

TAGGART, J. M. Gender segregation and cultural constructions of sexuality in two Hispanic societies. American Ethnologist, v. 19, n. 1, p. 75-96, 1992.

TIGER, L. Men in groups. New York: Marion Boyars, 1984.

TSING, A. L. In the realm of the Diamond Queen: marginality in an out-ofthe-way place. Princeton: Princeton University Press, 1993.

TUZIN, D. F. Ritual violence among the Ilahita Arapesh: the dynamics of moral and religious uncertainty. In: HERDT, G. (Ed.). Rituals of manhood: male initiation in Papua New Guinea. Berkeley: University of California Press, 1982. p. 321-355. 
TUZIN, D. F. The Cassowary's revenge: the life and death of masculinity in a New Guinea society. Chicago: University of Chicago Press, 1997.

VALDÉS, T.; OLAVARRÍA, J. (Org.). Masculinidad/es: poder y crisis. Santiago de Chile: ISIS Internacional, 1997.

VALDES, T.; OLAVARRÍA, J. (Org.). Masculinidades y equidad de género en América Latina. Santiago de Chile: FLACSO, 1998.

VIVEROS, M. Los estudios sobre lo masculino en América Latina: una producción emergente. Nómadas, n. 6, p. 55-65, 1997.

VIVEROS, M. Quebradores y cumplidores: biografías diversas de la masculinidad. In: VALDES, T.; OLAVARRÍA, J. (Org.). Masculinidades y equidad de género en América Latina. Santiago de Chile: FLACSO, 1998. p. 36-55.

VIVEROS, M.; GÓMEZ, F. La elección de esterilización masculina. In: MUJERES, HOMBRES Y CAMBIO SOCIAL. Bogotá: Facultad de Ciencias Humanas, Universidad Nacional de Colombia, 1998. p. 85-131.

WACQUANT, L. J. D. The pugilistic point of view: how boxers think and feel about their trade. Theory and Society, v. 24, n. 4, p. 489-535, 1995 a.

WACQUANT, L. J. D. Pugs at work: bodily capital and bodily labour among professional boxers. Body and Society, v. 1, n. 1, p. 65-93, $1995 \mathrm{~b}$.

WACQUANT, L. J. D. The prizefighter's three bodies. 1997. Manuscrito.

WEEKS, J. Sexuality and its discontents: meanings, myths, and modern sexualities. London: Routledge and Kegan Paul, 1985.

WELZER-LANG, D.; PICHEVIN, M.(Ed.). Des hommes et du masculin. Lyon: Presses Universitaires, Centre de Recherches et d'Etudes Anthropologiques, 1992.

WEST, M. M.; KONNER, M. J. The role of the father: an anthropological perspective. In: LAMB, M. E. (Ed.). The role of the father in child development. New York: John Wiley, 1976. p. 185-218. 
WESTON, K. Lesbian/gay studies in the house of anthropology. Annual Review of Anthropology, n. 22, p. 339-367, 1993.

WHITEHEAD, H. The bow and the burden strap: a new look at institutionalized homosexuality in Native North America. In: ORTNER, S. B.; WHITEHEAD, H. (Ed.). Sexual meanings: the cultural construction of gender and sexuality. Cambridge: Cambridge University Press, 1981. p. 80-115.

WHITING, B. B. (Ed.). Six cultures: studies of child rearing. New York: Wiley, 1963.

WHITING, B. B.; WHITING, J. W. M. Children of six cultures: a psychocultural analysis. Cambridge: Harvard University Press, 1975.

WHITING, J. W. M.; KLUCKHOHN, R.; ANTHONY, A. The function of male initiation ceremonies at puberty. In: MACCOBY, E. E. et al. (Ed.). Readings in social psychology. New York: Holt, Rinehart and Winston, 1958. p. 359-370.

WILLIAMS, W. The spirit and the flesh: sexual diversity in American Indian culture. Boston: Beacon, 1988.

WILLIS, P. Learning to labor: how working class kids get working class jobs. New York: Columbia University Press, 1979.

WILSON, C. Hidden in the blood: a personal investigation of AIDS in the Yucatan. New York: Columbia University Press, 1995.

YANAGISAKO, S. J.; COLLIER, J. F. Toward a unified analysis of gender and kinship. In: COLLIER, J. F.; YANAGISAKO, S. J. (Ed.). Gender and kinship: essays toward a unified analysis. Stanford: Stanford University Press, 1987. p. 14-50. 